\title{
Ecological Approaches in Textile Sector: The Effect of r-PET Blend Ratio on Ring Spun Yarn Tenacity
}

\author{
Esin Sarı̆ğlu \\ Gaziantep University, Faculty of Engineering, Textile Engineering Department, \\ 27310 Şehitkamil/Gaziantep, Turkey
}

\begin{tabular}{l} 
Article Info \\
\hline Article history: \\
Received May $27^{\text {th }}, 2017$ \\
Revised June $15^{\text {th }}, 2017$ \\
Accepted June $17^{\text {th }}, 2017$ \\
\hline
\end{tabular}

\section{Keyword:}

Elongation

Recycling

Ring spinning

r-PET

Tenacity

Virgin PET

\begin{abstract}
As the strategy of waste-management, it is very important to ensure that waste materials are recycled and reused in different industry in order to protect the ecological environment and there are so many initiatives related to this subject. Especially in the textile industry, recycling of PET bottle waste into recycled polyester fiber ( $r$-PET) has made a difference in the industry to reduce load on environment pollution. In addition, it contributes to reducing the fossil fuels sources, water and energy which is the required amount in the production of synthetic polymers. With supporting these attempts, we have to fulfill our social responsibility in order to preserve the ecological balance. This study aims to compare the tenacity and elongation properties of ring spun yarns produced from r-PET fibers recycled from waste PET bottles and cotton fiber at different blend ratios. Besides, virgin PET fibers were also used to conduct the difference between recycled and virgin fibers. Both r-PET and virgin PET fibers were blended with cotton as 100\%, 70\%/30\%, 50\%/50\% and $30 \% / 70 \%$ ratios. All production parameters were constant to determine the effect of raw materials on yarn tenacity and elongation. Results showed that ring spun yarns containing r-PET fibers had lower tenacity and elongation than virgin PET. On the other hand, the quality parameters of r-PET fibers can be improved by technological developments, and so they will be preferred to preserve the ecological balance.
\end{abstract}

\section{Corresponding Author:}

\section{Esin SARIOĞLU}

Gaziantep University, Faculty of Engineering,

Textile Engineering Department, 27310

Şehitkamil/ Gaziantep, Turkey.

Email: sarioglu@gantep.edu.tr

\section{Introduction}

Nowadays, climate change has serious problem for all over the world. To overcome this problem some attempts have been performed by governments to minimize waste generation or reuse wastes. Polyethylene terephthalate (PET) bottles are produced from raw petrochemical products and waste after use has not affect environment directly. On the other hand, the increasing volume of PET bottle waste causes economical and environmental problems unless to be recycled [1]. But it is becoming critical problems, besides environmental and economic awareness, legislations has started to minimize the solid residues [2]. Meanwhile, recycling of post-consumer PET bottles has become a well-established system with its own logistic chain including bottles collection, flake production and pellet production [3]. Besides, recycling of PET bottles leads to decrease waste problem and use of raw petrochemical products, water and energy. Furthermore, it has been approximated that PET bottle recycling gives a benefit in greenhouse gas emissions of 1.5 tons of $\mathrm{CO} 2$ per tones of recycled PET [4]. On the other hand, recycling of PET bottles and using in textile industry give textile products an added value $[5,6]$. Recycling processes which can be mechanical or chemical are the best 
way to reduce PET wastes into reused forms economically [7-10]. Furthermore, recycling process does not reduce cost but it is essential to conserve ecological balance.

PET bottles can be easily separated from other wastes, some additional processes are needed ie. breaking, washing, drying to obtain PET flakes. r-PET fibers to be used in textile industry are produced by melt spinning system from PET flakes. This recycled product can easily be adapted to textile product production instead of virgin PET. Approximately $60 \%$ of recycled PET polymer is used in the production of PET filament and staple fiber, this situation shows how important industry of textile [6]. Some researchers have focused on the usability and adaptability of r-PET fiber in textile industry [7,11-16].

This study aims to determine and compare the effect of using r-PET fiber with different blend ratio on ring spun yarn tenacity and elongation. At this respect, r-PET and virgin PET fibers (PET) were blended with cotton fiber at $100 \%, 70 \% / 30 \%, 50 \% / 50 \%, 30 \% / 70 \%$ ratio, separately. Yarn samples were manufactured by ring spinning system and all production parameters were kept constant to evaluate the effect of blend ratio and raw material variables.

\section{Materials and Methods}

This study was achieved as cooperation with Gama Textile Company in Gaziantep/Turkey. r-PET fiber were produced by collecting, rating, washing and breaking, drying and reducing the size of PET bottles to obtain PET flakes. Then, PET flakes were converted into r-PET fiber by melt spinning process. The properties of r-PET fiber, virgin PET fiber and cotton fiber were given in Table 1. Fibers were weighted according to blend ratio and blended with sandwich blend method at the beginning of the blowroom. In the process order of the yarn production, carding, three passage drawframe, roving processes were carried out. 656 tex slivers were used and 19.7 tex yarns with $\alpha_{e}=3.39$ (730 TPM) twist level were produced as $100 \%$ r-PET, $100 \%$ virgin PET and cotton blends $(70 \% / 30 \%, 50 \% / 50 \%$ and 30\%/70\%) by ring spinning system at $13.500 \mathrm{rpm}$ spindle speed. $100 \%$ cotton ring spun yarn was manufactured with $\alpha_{e}=3.71$ (800 TPM) twist level at the same spindle speed.

Table 1. Properties of raw materials

\begin{tabular}{lccc}
\hline \multirow{2}{*}{ Properties } & \multicolumn{3}{c}{ Raw Material } \\
& r-PET & PET & Cotton \\
\hline Fineness, dtex & 1.30 & 1.30 & $1.70^{*}$ \\
Length, mm & 38 & 32 & 31.98 \\
\hline *4.32 Micronaire (dtex cotton=Micronaire*0.394) & &
\end{tabular}

All yarn tests were carried out after conditioning the specimens in a standard atmosphere at $20 \pm 2{ }^{\circ} \mathrm{C}$ temperature and $65 \pm 4 \%$ relative humidity for 24 hours according to the standard of BS EN ISO 139:2005+A1:2011. Tenacity and elongation measurements of yarn samples were achieved with Uster® Tensorapid-4 according to BS EN ISO 2062:2009. Ten tests were performed in each 4 bobbins and reported values represent the average of those test results.

SPSS 22.0 package program at $95 \%$ confidence interval was used for multivariate analysis of variance (MANOVA) in order to determine the significance effect of raw material and blend ratio on yarn tenacity and elongation. Furthermore, Duncan's new multiple range test was provided in order to compare the difference between the means of treatment subgroups of blend ratios in analysis of variance was provided at significance level of 0.05 .

\section{Results and Discussion}

In Figure 1, tenacity of yarn samples composed of PET/CO and r-PET/CO at different blend ratio is shown. It is obvious that yarns containing virgin PET fiber have higher tenacity than that of r-PET fiber. This decrease was expected because of the lower tenacity of r-PET fibers than PET fibers $[13,16]$. On the other hand, the increase in the synthetic blend ratio leads to higher tenacity of yarns both containing virgin PET and r-PET fibers. It is seen that, 50\%/50\% r-PET/CO blend yarn tenacity is lower as $1.81 \mathrm{cN} / \mathrm{tex}$ than $30 \% / 70 \%$ r-PET/CO yarn tenacity.

Elongation at breaks histograms are illustrated in Figure 2. In all blend ratios of r-PET and PET fibers, it is seen that synthetic fibers contribute the elongation with respect to $\mathrm{CO}$ yarn. The results contributed with the 
information already present in the literature $[13,16]$. It can be probably said that yarns produced with $100 \%$ r-PET yarn have highest result than $100 \%$ PET yarn.

MANOVA analysis of dependent variables (tenacity and elongation) between subjects is given in Table 2 . Raw materials and blend ratio have a significant effect on breaking strength at $\alpha=0.05$ confidence interval.

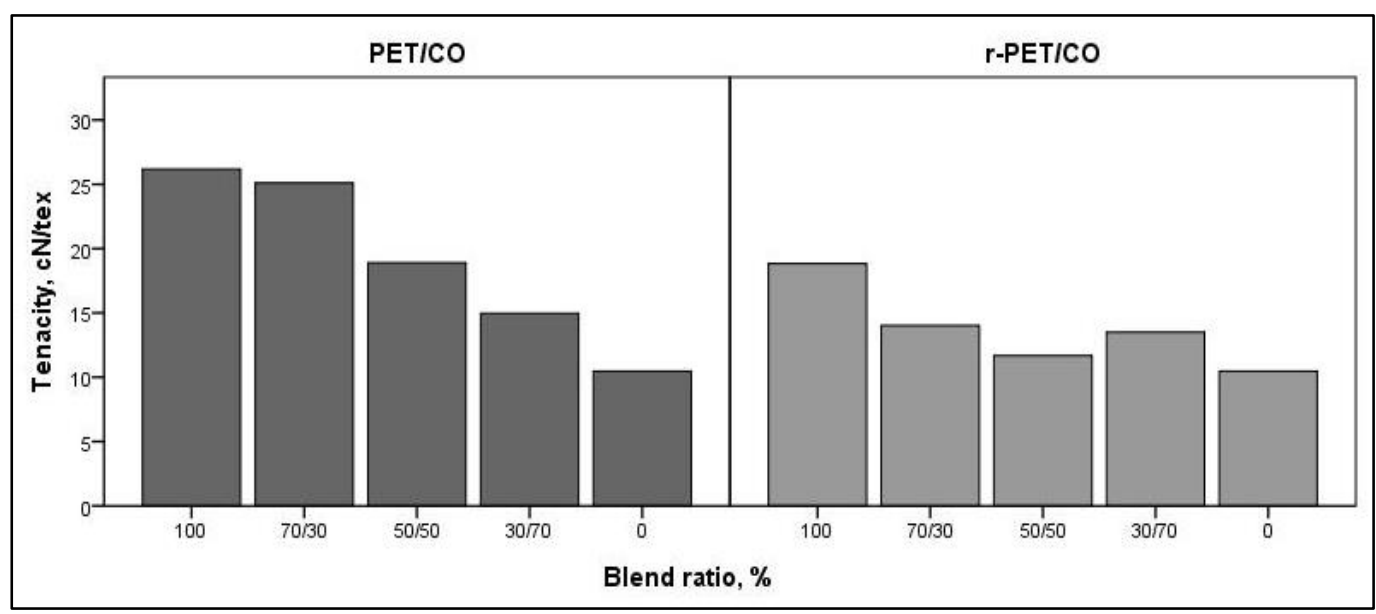

Figure 1 . Tenacity of yarns

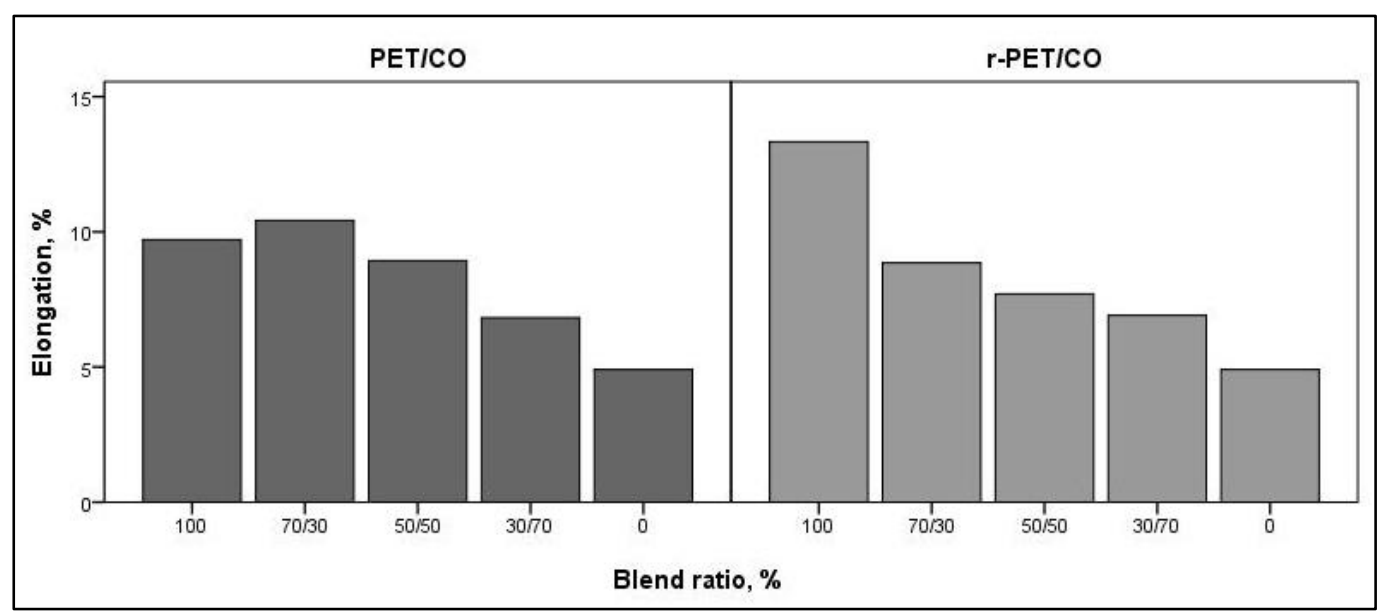

Figure 2. Elongation of yarns

The coefficient of variation $\left(\mathrm{R}^{2}\right)$ is a measurement of "goodness of fit" and ranges from " 0 " to " 1 ". Analysis explains about $94.8 \%$ of the variability in yarn tenacity for all yarn samples and it is evaluated as statistically significant for all independent variables $(p<0.05)$. On the other hand, the effect of raw materials on yarn elongation is not found statistically important $(p=0.462)$. It can be said that the elongation of $r$-PET and virgin PET blended yarns are close to each other and there is no difference statistically. Besides, blend ratio has statistically significant effect on yarn elongation. $\mathrm{R}^{2}$ is determined as $93.1 \%$ with the high value.

From pair wise comparison of the mean tenacity, using Duncan tests, results at a significance level of 0.05 for blend ratio parameter trend is observed that the higher blend ratio of PET and r-PET raw materials (70\%/30\% and $100 \%$ ) yarns has the higher tenacity than CO yarn which is represented as " $0 \%$ " blend ratio (Table 3 ). It is clearly seen in Table 3, there is no significant difference between at 30\%/70\% and $50 \% / 50 \%$ blend ratios $(p>0.05)$. Table 4 illustrates Duncan's multivariate range test results of the mean elongation at a significance level of 0.05 . The higher the PET or r-PET blend ratio the higher the elongation at break of ring spun yarn is obtained and also $100 \% \mathrm{CO}$ yarn has the lowest elongation value.

Table 2. MANOVA results of between subject effects

\begin{tabular}{llccccc}
\hline Source & $\begin{array}{l}\text { Dependent } \\
\text { Variable }\end{array}$ & $\begin{array}{c}\text { Sum of } \\
\text { Squares }\end{array}$ & df & $\begin{array}{c}\text { Mean } \\
\text { Square }\end{array}$ & F & Sig. \\
\hline \multirow{2}{*}{ Corrected Model } & Tenacity, cN/tex & $1169.208^{\mathrm{a}}$ & 9 & 129.912 & 60.561 & .000 \\
& Elongation, \% & $240.039^{\mathrm{b}}$ & 9 & 26.671 & 45.271 & .000 \\
\hline
\end{tabular}




\begin{tabular}{llccccc}
\hline \multirow{2}{*}{ Intercept } & Tenacity, cN/tex & 10774.806 & 1 & 10774.806 & 5022.900 & .000 \\
& Elongation, \% & 2721.510 & 1 & 2721.510 & 4619.410 & .000 \\
\hline \multirow{2}{*}{ Raw materials } & Tenacity, cN/tex & 294.415 & 1 & 294.415 & 137.248 & .000 \\
& Elongation, \% & .328 & 1 & .328 & .556 & .462 \\
\hline \multirow{2}{*}{ Blend ratio } & Tenacity, cN/tex & 706.663 & 4 & 176.666 & 82.356 & .000 \\
\multirow{2}{*}{ Raw materials* } & Elongation, \% & 205.944 & 4 & 51.486 & 87.391 & .000 \\
\hline \multirow{2}{*}{ Blend ratio } & Elongaty, cN/tex & 168.130 & 4 & 42.033 & 19.594 & .000 \\
\multirow{2}{*}{ Total } & Tenacity, cN/tex & 63.767 & 4 & 8.442 & 14.329 & .000 \\
\hline \multirow{2}{*}{ Corrected Total } & Elongation, \% & 17.674 & 30 & 2.145 & - & - \\
& Tenacity, cN/tex & 12008.369 & 40 & - & - & - \\
\hline \multirow{2}{*}{ E } & Elongation, \% & 2979.223 & 40 & - & - & - \\
\cline { 2 - 7 } & Elongation, \% & 1233.563 & 39 & - & - & - \\
\hline
\end{tabular}

a. R Squared $=.948($ Adjusted R Squared $=.932)$

b. R Squared $=.931$ (Adjusted R Squared $=.911)$

Table 3. Effect of blend ratio on tenacity; based on means observed. Error term is the mean square $($ Error $)=2.145$. a. Uses harmonic mean sample size $=8.000, \mathrm{~b}$. Alpha $=0.05$

\begin{tabular}{cccccc}
\hline \multicolumn{6}{c}{ Duncan $^{\mathrm{a}, \mathrm{b}}$} \\
\hline \multirow{2}{*}{ Blend ratio } & \multirow{2}{*}{$\mathrm{N}$} & \multicolumn{4}{c}{ Subset } \\
\cline { 3 - 6 } & & 1 & 2 & 3 & 4 \\
\hline $0 \%$ & 8 & 10.48 & & & \\
$30 \% / 70 \%$ & 8 & & 14.23 & & \\
$50 \% / 50 \%$ & 8 & & 15.29 & & \\
$70 \% / 30 \%$ & 8 & & & & 22.57 \\
$100 \%$ & 8 & & & & \\
Sig. & & 1.000 & .156 & 1.000 & 1.000 \\
\hline
\end{tabular}

Table 4. Effect of blend ratio on elongation; based on means observed. Error term is the mean square (Error) $=0.589$. a. Uses harmonic mean sample size $=8.000, \mathrm{~b}$. Alpha $=0.05$

\begin{tabular}{|c|c|c|c|c|c|c|}
\hline \multicolumn{7}{|c|}{ Duncan $^{\mathrm{a}, \mathrm{b}}$} \\
\hline \multirow{2}{*}{ Blend ratio } & \multirow[b]{2}{*}{$\mathrm{N}$} & \multicolumn{5}{|c|}{ Subset } \\
\hline & & 1 & 2 & 3 & 4 & 5 \\
\hline $0 \%$ & 8 & 4.9025 & & & & \\
\hline $30 \% / 70 \%$ & 8 & & 6.8663 & & & \\
\hline $50 \% / 50 \%$ & 8 & & & 8.3163 & & \\
\hline $70 \% / 30 \%$ & 8 & & & & 9.6375 & \\
\hline $100 \%$ & 8 & & & & & 11.520 \\
\hline Sig. & & 1.000 & 1.000 & 1.000 & 1.000 & 1.000 \\
\hline
\end{tabular}

\section{Conclusion}

This study was focused on the effect of raw materials and blend ratio of r-PET and PET containing CO ring spun yarn at finer count ( $\mathrm{Ne} \mathrm{30/1)}$ on yarn tenacity and elongation. It was concluded that blend ratio has statistically significant effect on yarn tenacity and elongation. All these results showed that apparel containing r-PET fiber must be taken into consideration which has an alternative to virgin PET fiber in some aspect. It is not be denied that some attempts have been done by using r-PET fiber in order to contribute the ecological balance. The price of r-PET fiber is similar to virgin PET fiber because of the essential processes to degrade and recycle PET bottle. It is clear that despite the cost the consumption of ecologically friendly r-PET fiber seems to be seriously increased. 


\section{Acknowledgements}

Author thanks Gama Textile Company for r-PET fiber supplying from their recycling company and contribution for yarn samples production of this study. The author also thanks Karacasu Textile Company, who supplied virgin polyester fiber.

\section{References}

[1] L. Bartolome, M. Imran, B.G. Cho, W.A. Al-Masry and D.H. Kim, "Recent developments in the chemical recycling of PET," Material Recycling - Trends and Perspectives, InTech publisher, pp.65-84, 2012.

[2] R.A. Sanches, K. Takamune, B. Guimaraes, R. Alonso, J.Baruque-Ramos, M.S. Barros de Held and J.P.P. Marcicano, "Wearability analysis of knitted fabrics produced with colored organic cotton, bamboo rayon, corn, recycled pet/cotton and recycled pet/polyester," American International Journal of Contemporary Research, vol.4, issue.4, pp.29-37, April 2014.

[3] L. Shen, E. Worrell and M.K. Patel, "Open-loop recycling: A LCA case study of PET bottle-to-fibre recycling," Resources, Conservation and Recycling, vol.55, pp.34-52, 2010.

[4] J. Hopewell, R. Dvorak and E. Kosior, "Plastics recycling: challenges and opportunities," Phil.Trans.R.Soc.B, issue.364, pp.2115-2126, 2009.

[5] F. Awaja and D. Pavel, "Recycling of PET," European Polymer Journal, vol.41, pp.1453-1477, 2005.

[6] A. Telli, N. Özdil and O. Babaarslan, "Usage of PET bottle wastes in textile industry and contribution to sustainability, Journal of Textiles and Engineer, vol.19, issue.86, pp.49-55, 2012.

[7] R.A. Sanches, K. Takamune, B.M. Guimaraes, R.S. Alonso, D. Karam Jr, J.P.P. Marcicano, A.Y. Sato Duarte, F.G. Dedini, "Comparative study of characteristics of knitted fabrics produced from recycled fibres employing the chauvenet criterion, factorial design and statistical analysis,". Fibres \& Textiles in Eastern Europe, vol.23, issue. 4(112), pp.19-24, 2015.

[8] J.C. Tapia-Picazo, J.G. Luna-Barcenas, A. Garcia-Chavez, R. Gonzales-Nunez, A. Bonilla-Petriciolet and A. Alvarez-Castillo, "Polyester fiber production using virgin and recycled PET," Fibers and Polymers, vol.15, issue.3, pp.547-552, 2014.

[9] A.E. Tayyar and S. Üstün, "Usage of recycled PET," Pamukkale University Engineering Science Journal, vol.16, issue.1, pp.53-62, 2010.

[10] I.A. Ignatyev, W. Thielemans and B.V. Beke, "Recycling of polymers: a review," ChemSusChem, vol.7, pp.1579-1593, 2014.

[11] A.Telli and N. Özdil, "Effect of recycled PET fibers on the performance properties of knitted fabrics," Journal of Engineered Fibers and Fabrics, vol.10, issue.2, pp.47-60, 2015.

[12] R. Atakan, "Use of recycled poly (ethylene terephtalate) fibers in needlepunched automotive carpets," Istanbul Technical University, Institute of science and Technology, Department of Textile Engineering, M.Sc. Thesis, pages. 91, 2014.

[13] M.E. Yüksekkaya, G. Celep, G. Doğan, M. Tercan and B. Urhan, "A comparative study of physical properties of yarns and fabrics produced from virgin and recycled fibers" Journal of Engineered Fibers and Fabrics, vol.11, issue.2, pp.68-76, 2016.

[14] I.Mari and Y. Shinji, "Performance and durability of woven fabrics including recycled polyester fibers," Journal of Textile Engineering, vol.50, issue.2, pp.25-30, 2004.

[15] S. Rajamanickam and K. Vasudevan, "Study of antibacterial activity of chitosan on lyocell and recycled polyester yarns," International Journal of Innovative Research in Science, Engineering and Technology, vol.3, issue.2, pp.9480-9486, February 2014.

[16] A. Telli and N. Özdil, "Properties of the yarns produced from r-pet fibers and their blends," Tekstil ve Konfeksiyon, vol.23, issue.1, 2012. 